\title{
CLINICAL AND RADIOGRAPHIC EVALUATION OF HYALURONIC ACID AS A VITAL PULPOTOMY MEDICATION IN PRIMARY MOLARS
}

\author{
Shaimaa M. Mahfouz ${ }^{*}$, Asmaa Y. Abd-allah ${ }^{* *}$ and Shaimaa S. El-Desouky ***
}

\begin{abstract}
Background: To assess \& compare clinical \& radiographic effects of Hyaluronic acid (HA) versus formocresol (FC) as pulpotomy medication in primary molars.

Materials \& Methods: 20 children in age group 4-7 years have bilateral primary molars which need pulpotomy treatment due to deep caries. children divided into two groups, group I included 20 molars treated with HA \& group II included 20 molars treated by FC. Patients were recalled after 3 , 6 , and 12 months for clinical and radiographical evaluation.
\end{abstract}

Results: Clinically all cases showed no signs of pain, gingival swelling, or mobility in both HA, FC group except at 12 months. Radiographically, both HA, FC groups revealed no internal resorption at 3,6 months while at 12 months only one case of FC group, three cases of HA group showed internal resorption. FC group revealed increase in the PDL space at 3,6 and 12-months while HA group showed decrease in PDL space at 3 and 6 months then slight increase occurred at 12 months. FC group revealed furcation radiolucency increase at 3, 6 and 12 months while HA group showed slight decrease in bone radio-density at 3 months then an increase in bone radiodensity at 6 months followed by a decrease at 12 months.

Conclusion: Clinical and radiographic success rates of HA is comparable to FC for primary molars over 12 month follow-up period.

Recommendation: Further clinical studies with long time evaluation periods should be done to investigate HA effects on primary pulp tissues.

KEYWORDS: Hyaluronic acid, Formocresol, Pulpotomy

\footnotetext{
* Assistant Professor Pediatric, Preventive and Dental Public Health, Faculty of Dentistry, Suez Canal University.

** Lecturer Oral Radiology Department, Faculty of Dentistry, Suez Canal University

*** Lecturer Pediatric Dentistry, Oral Health and Preventive Dentistry Department, Faculty of Dentistry, Tanta University
} 


\section{INTRODUCTION}

Primary dentition in an intact state is a major goal in pediatric dentistry until the eruption of permanent successors. ${ }^{(1)}$ The main purpose of pulp therapy in primary dentition is to keep each primary tooth functioning in the dental arch to permit proper mastication, speech, arch length preservation, and the prevention of abnormal oral habits. ${ }^{(2)}$

Pulpotomy is the most widely accepted technique for treating primary teeth with deep carious lesion, pulp exposure during the operatory process or after a traumatic pulp exposure. ${ }^{(3)}$ Pulpotomy is the surgical removal of inflamed coronal pulp tissue leaving the vital radicular pulp intact. ${ }^{(4)}$ The success of a pulpotomy technique is based on both a proper diagnosis of the inflamed dental pulp and good choice of a therapeutic medicament ${ }^{(5)}$ which should be bactericidal and non-toxic to cells and surrounding tissues, as well as stimulate healing of the remaining radicular pulp tissue. ${ }^{(6)}$

Formocresol (FC) is the "gold standard" pulpotomy medicament for primary teeth in the last 70 years, it was introduced by Sweet in 1932 with a success rate of $97 \%$. It consists of $19 \%$ formaldehyde, $35 \%$ cresol in a vehicle of $15 \%$ glycerin and water (Buckley's solution). Formocresol induces liquefaction necrosis in the neighboring pulp tissue with the fixative effect reducing apically as the apical third of the pulp remains unchanged and vital for long time. ${ }^{(2,7)}$ Recently, many reservations have been conveyed to the use of formocresol due to the potential systemic spread of FC molecules through the root canals lead to potential cytotoxicity, possible mutagenicity and carcinogenicity and alterations in immune response. ${ }^{(8,10)}$ Moreover, it was reported that an association presents between primary teeth treated with FC and enamel defects in their permanent successors. Hence, researchers have continued their efforts in the direction for invention of new dental materials with better properties and promising results over pulp healing process than Formocresol. ${ }^{(2)}$
Many different compounds have been suggested include glutaraldehyde, electrosurgery, calcium hydroxide, ferric sulfate, freeze-dried bone, bone morphogenic proteins (BMP), mineral trioxide aggregate (MTA) and Biodentine (Tricalcium Silicate Cement) as replacement for FC in pulpotomy procedure however, there is still no entirely suitable agent for replacement. ${ }^{(1,11-14)}$

Hyaluronic acid (HA) or hyaluronan is a hydrated anionic polysaccharide plentiful in the extracellular matrix with a molecular weight of 4000$20,000,000 \mathrm{Da}$ that is found in a variety of tissues including skin, synovial fluid, cartilage, tendons, eyes and embryonic mesenchyme ${ }^{(15,16)}$ It is comprised of repeating disaccharides d-glucuronic acid and $\mathrm{N}$ acetyl-d-glucosamine, which are joined together by alternating $\beta-1,4$ and $\beta-1,3$ glycoside bonding ${ }^{(17,18)}$. During bone repair, it encourages the undifferentiated mesenchymal cells to migrate, adhere, and proliferate into osteoblastic cells. ${ }^{(19-21)}$ Due to its non-toxicity, biocompatibility, biodegradability and non-immunogenicity, exogenous hyaluronic acid is used topically and systemically to modulate and accelerate the host response through mechanisms defined in a variety of medical fields, including dermatology ${ }^{(22)}$ ophthalmology, ${ }^{(23)}$ and orthopedics as an anti-inflammatory agent.

Pagnacco and Vangelisti, in $1997^{(24)}$, performed the first clinical trials in dentistry. HA has been shown to have anti-inflammatory, anti-edematous, and anti-bacterial effects for periodontal disease treatment. ${ }^{(25)}$ Also, major improvements were observed after aesthetic reconstruction of interdental papilla loss. ${ }^{(26)}$ Furthermore, the use of a gel containing amino acids \& HA facilitated faster healing in laser-induced wounds by secondary intention ${ }^{(27)}$. HA tends to be helpful in the treatment of swelling and trismus ${ }^{(28)}$ as well as the inflammatory reaction after third molar extraction. ${ }^{(29)}$

The use of a hyaluronic acid to cover a dentin defect, stimulated a cell-rich rearrangement of 
pulp tissue with few inflammatory cells, as well as being an acceptable and biocompatible scaffold for regenerating the dental pulp. ${ }^{(30)}$ Because of its high molecular weight when dissolved in water, hyaluronic acid's viscoelasticity increases, making it simpler to use as an injectable scaffold. ${ }^{(31,32)}$ Moreover, advantageous characteristics are related to the hyaluronic acid scaffolds as bioactivity, biocompatibility, biodegradability, in addition to serving as a reservoir for growth factors. ${ }^{(33)}$

To date, only limited studies are available to evaluate Hyaluronic acid sponge for the pulpotomy of primary teeth. Hence, this study was performed to evaluate the clinical \& radiographic effect of Hyaluronic acid gel (HA) and formocresol (FC) in primary molars as a pulpotomy agent.

\section{MATERIALS AND METHODS}

The sample size was calculated using $\mathrm{G}^{*}$ Power The effect size was 0.47 using alpha $(\alpha)$ level of 0.05 and Beta $(\beta)$ level of 0.05 , i.e., power $=95 \%$; the estimated minimum sample size (n) was a total of 40 teeth. 20 teeth for each group.

A randomized, controlled prospective clinical study was done at Pediatric Dentistry Department Outpatient clinic, Suez Canal University after obtaining the approval of the ethical committee (REC), Faculty of Dentistry, Suez Canal University, code (307/2020) and an informed written consent from parents. A sample of 40 teeth from 20 children in age group 4-7 years had bilateral primary molars which need dental treatment due to deep caries and indicated for vital pulpotomy procedure that was confirmed by clinical examination \& pre-operative periapical $x$ ray. Primary molars were divided into two groups, (group I) included (20) molars were treated with hyaluronic acid gel (HA)* and the other (group II) included (20) molars were treated by $1 / 5$ formocresol (FC) ${ }^{* *}$ using split mouth technique.

\section{Inclusion criteria $^{(8)}$}

\section{A-Clinical criteria}

1. Restorable mandibular primary molars with deep carious lesions.

2. Absence of gingival swelling or sinus tract.

3. Absence of spontaneous pain

4. Absence of pain on percussion.

\section{B-Radiographic criteria}

1-Absence of discontinuity of lamina dura

2-Absence of internal root resorption.

3-Absence of external root resorption.

4-Absence of inter-radicular or periapical bone destruction (radiolucency).

\section{Technique}

Clinical and radiographic examinations were performed for each tooth before treatment. Teeth were anesthetized using Mepecaine -L.A (local anesthetic solution containing $20 \mathrm{mg}$ Mepivacaine hydrochloride. Rubber dam and high suction were used in pulpotomy procedure. Cavity outline was performed by sterile \#330 high speed bur using water spray. Caries was removed by large spoon excavator. When pulpal exposure occurred, the roof of pulp chamber removed by low speed round bur. Hemostasis was obtained by applying pressure with moist cotton pellet with saline. If bleeding has not stopped within $5 \mathrm{~min}$, tooth was excluded from study. Then the test materials was applied as follow: Experimental group (I): (20) Teeth were treated with Hyaluronic acid gel freshly mixed with zinc oxide powder till reach suitable consistency (1:1 ratio by volume) to cover pulp stumps, Control group (II): (20) Teeth were treated by using sterile cotton pledget with formcresol for 3-5 min then, removed. Then pulp stumps of all molars in each group were dressed with thick paste prepared by mixing zinc oxide powder with one drop of eugenol $^{* * *}$. Intermediate restorative material

\footnotetext{
* Cute gel Korea

** Prevest-dentopro dental

*** Meta Biomed
} 
(reinforced zinc oxide eugenol, IRM®*) was placed over the zinc oxide eugenol layer, then the tooth was restored with a preformed stainless steel crown ${ }^{* *}$.

\section{Evaluation Methods:}

a) Clinical follow up: The clinical follow up evaluation was carried out after three, six and twelve months after pulpotomy procedures. The teeth were clinically evaluated each follow up visit for the following clinical features: presence or absence of spontaneous pain, tooth mobility and sensitivity to percussion, as well as examination of any changes of the mucobuccal folds for presence or absence of swelling, sinus, draining fistula or abscess. If the tooth exhibited any one of above clinical features, the pulpotomy was considered to be a failure (F); otherwise, it was regarded as clinical success (S).

b) Radiographic follow up: Radiographic evaluation was performed immediately after teeth restoration (base line radiograph), then after three, six and twelve months. Direct standardized digital radiographs were achieved using Vista Ray Charged Coupled device ${ }^{* * * *}$. The CCD sensor size dimensions are: $27.4 \times 39.0 \times 6.3 \mathrm{~mm}$ (W x H x D mm) and it has active surface area of $20 \times 30 \mathrm{~mm}$. Pixel size is $19 \times 19$ microns with total pixel number of $1,659,000$ pixels.

The parallel periapical technique was performed using the rinn (XCP) periapical film holder ${ }^{* * * *}$ and a long cone (sixteen inch in length) which was mounted to the $\mathrm{x}$-ray tube and the plastic aiming ring of XCP film holder was fixed flush-ended with the round end of the long cone. The sensor was placed horizontally in the film holder opposite to the pulpotomized teeth.

\footnotetext{
* IRM ${ }^{\circledR}$ DENTSPLY International, USA

** $3 \mathrm{M}^{\mathrm{TM}}$ Unitek $^{\mathrm{TM}}$

*** Vista Ray sensor 7.1, DURR.DENTAL, Germany

***** Rinn Corporation, Elign, IL

***** Fona XCD, ViaGalilei, Assago, Italy

******* Wayne Rasband, National Institute of Health, USA
}

The sensor was exposed to x-ray Fona intra oral $\mathrm{x}$-ray machine ${ }^{* * * * *}$ with $70 \mathrm{kvP}$ and $6 \mathrm{~mA}$ for 0.06 seconds exposure parameters. The central ray was directed perpendicular to the sensor. Radiometric and radio-densitometric analysis of the radiographs were carried out using the software Image $\mathrm{J} 1.44 \mathrm{p}^{* * * * * *}$.

The same radiographic records were obtained and measured twice at different times by the same examiner (second author), who was blind to type of medication used. The average reading was recorded and used for comparisons between successive radiographs and for statistical analysis. Teeth were radiographically evaluated for width of the periodontal membrane space in the furcation area (exactly at the middle of the furcation area and assessed in millimeters), presence or absence of internal and external root resorption, and radiodensity of bone at the furcation area to assess the effect of the puplotomy medicament on alveolar bone.

The Region Of Interest (ROIs) were picked and analyzed and the mean values of radio-density was measured at the middle of the furcation area. The same area was measured in successive radiographs and the average radio-density were recorded for the follow up radiographs (Figure 1).

\section{Statistical Analysis}

All data was collected, tabulated, and statistically analyzed. Chi-square test was used to test significance of association between categorical variables. In order to compare mean difference between groups, independent samples-t test was used. The significance level was set as $\mathrm{P}$ value $\leq 0.05$ is significant. Statistical analysis was performed using SPSS version 16. 


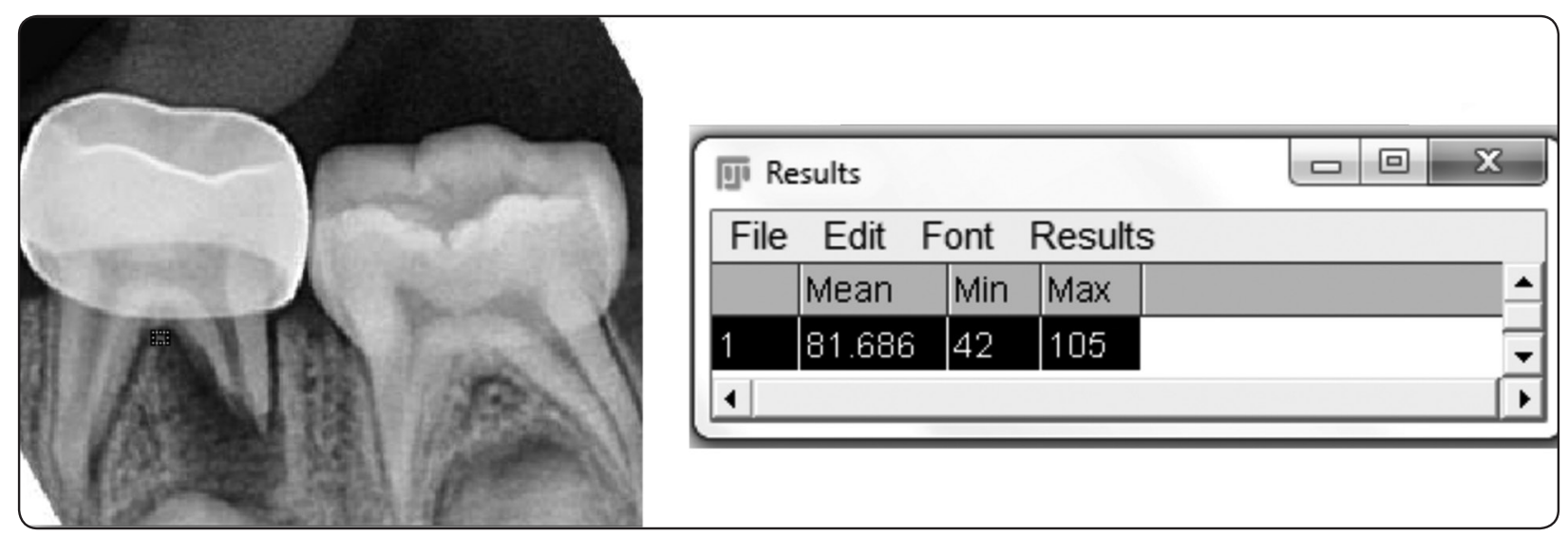

Fig. (1): Radiograph showing the inter-radicular alveolar bone density using ImageJ software.

\section{RESULTS}

Vital pulpotomy was performed on forty mandibular primary molars out of 20 children selected from Outpatient clinics of Pediatric Dentistry Department, Faculty of Dentistry, Suez Canal University however one patient was lost leaving 19 patients. All patients were evaluated clinically and radiographically at three, six \& twelve months.

\section{Clinical evaluation}

In HA group, during all the follow-up periods, all cases showed no signs of pain, gingival swelling, or mobility except at 12 months, two cases $(10.5 \%)$ came with gingival swelling, seven cases $(36.84 \%)$ felt pain with percussion and nine cases $(47.37 \%)$ came with mobility. Regarding FC group, all cases showed no signs of pain, gingival swelling, or mobility except at 12 months, one case $(5.3 \%)$ came with gingival swelling, two cases $(10.5 \%)$ felt pain with percussion and exhibit mobility. There were no statistically significant differences between the two groups as shown in Table 1, Figure 2. All failed cases were managed by pulpectomy or extraction and space maintainer.

\section{Radiographic evaluation:}

Throughout the follow-up periods, FC treated teeth revealed no evidence of internal resorption or external root resorption at 3,6 months follow-up periods while at 12 months, only one case (5.3\%) showed internal and external resorptions. In HA group, all treated teeth revealed no evidence of internal resorption at 3,6 months follow-up periods except at 12 months, three cases $(15.8 \%)$ showed internal resorption. While $26.3 \%, 36.8 \%$ and $63.2 \%$ of HA treated teeth revealed external root resorption at 3, 6 and 12-months follow-up periods, respectively. There were no statistically significant differences between the two groups as shown in Table $(2,3) \&$ Figure $(3,4,7)$.

Regarding periodontal ligament (PDL) space, FC treated teeth revealed increase in the PDL space at 3, 6 and 12-months follow-up periods while HA treated teeth showed decrease in PDL space at 3 and 6 months follow-up periods then slight increase occurred at 12 months follow-up period. There was a highly statistically significant difference at 3, 12 months follow-up periods between the two groups as shown in table (4) \& figure (5).

In relation to furcation bone radio-density, FC treated teeth revealed increase in furcation radiolucency at 3, 6 and 12-months follow-up periods while HA treated teeth showed slight decrease in bone radio-density at the furcation area at 3 months follow-up period. It was observed an increase in bone radio-density at 6 months followup period for HA group followed by a decrease at 12 months follow-up period. There was a highly statistically significant difference at 3, 6, 12 months follow-up periods between the two groups as shown in table (5) \& figure (6). 
TABLE (1) Clinical evaluation of HA, FC groups according to presence of failure criteria at different followup periods

\begin{tabular}{|c|c|c|c|c|c|c|c|c|c|c|c|c|c|c|c|c|}
\hline & \multicolumn{4}{|c|}{ Pain } & \multicolumn{4}{|c|}{ Fistula formation } & \multicolumn{4}{|c|}{ Pain with percussion } & \multicolumn{4}{|c|}{ Mobility } \\
\hline & \multicolumn{2}{|c|}{ HA } & \multicolumn{2}{|c|}{$\mathrm{FC}$} & \multicolumn{2}{|c|}{ HA } & \multicolumn{2}{|c|}{$\mathrm{FC}$} & \multicolumn{2}{|c|}{ HA } & \multicolumn{2}{|c|}{$\mathrm{FC}$} & \multicolumn{2}{|c|}{ HA } & \multicolumn{2}{|c|}{$\mathrm{FC}$} \\
\hline & $\mathrm{n}$ & $\%$ & $\mathrm{n}$ & $\%$ & $\mathrm{n}$ & $\%$ & $\mathrm{n}$ & $\%$ & $\mathrm{n}$ & $\%$ & $\mathrm{n}$ & $\%$ & $\mathrm{n}$ & $\%$ & $\mathrm{n}$ & $\%$ \\
\hline Base line & $0 / 19$ & $0.0 \%$ & $0 / 19$ & 0.0 & $0 / 19$ & 0.0 & $0 / 19$ & 0.0 & $0 / 19$ & 0.0 & $0 / 19$ & 0.0 & $0 / 19$ & 0.0 & $0 / 19$ & 0.0 \\
\hline $3 \mathrm{~ms}$ & $0 / 19$ & $0.0 \%$ & $0 / 19$ & 0.0 & $0 / 19$ & 0.0 & $0 / 19$ & 0.0 & $0 / 19$ & 0.0 & $0 / 19$ & 0.0 & $0 / 19$ & 0.0 & $0 / 19$ & 0.0 \\
\hline $6 \mathrm{~ms}$ & $0 / 19$ & $0.0 \%$ & $0 / 19$ & 0.0 & $0 / 19$ & 0.0 & $0 / 19$ & 0.0 & $0 / 19$ & 0.0 & $0 / 19$ & 0.0 & $0 / 19$ & 0.0 & $0 / 19$ & 0.0 \\
\hline $12 \mathrm{~ms}$ & $0 / 19$ & $0.0 \%$ & 0/19 & 0.0 & $2 / 19$ & 10.53 & $1 / 19$ & 5.26 & $7 / 19$ & 36.84 & $2 / 19$ & 10.53 & $9 / 19$ & 47.37 & $2 / 19$ & 10.53 \\
\hline $\begin{array}{c}\text { Chi square } \\
\left(\chi^{2}\right)\end{array}$ & \multicolumn{4}{|c|}{0.00} & \multicolumn{4}{|c|}{0.11} & \multicolumn{3}{|c|}{0.878} & \multicolumn{5}{|c|}{1.377} \\
\hline $\begin{array}{c}\text { P-value } \\
<0.05\end{array}$ & \multicolumn{4}{|c|}{1.00} & \multicolumn{4}{|c|}{0.99} & \multicolumn{3}{|c|}{0.831} & \multicolumn{5}{|c|}{0.710} \\
\hline
\end{tabular}

TABLE (2) Radiographic evaluation of HA, FC groups according to presence of internal resorption at different follow-up periods

\begin{tabular}{|c|c|c|c|c|}
\hline \multirow{2}{*}{} & \multicolumn{2}{|c|}{$\mathrm{HA}$} & \multicolumn{2}{c|}{$\mathrm{FC}$} \\
\cline { 2 - 5 } & $\mathrm{n} / \mathrm{N}$ & $\%$ & $\mathrm{n} / \mathrm{N}$ & $\%$ \\
\hline Base line & $0 / 19$ & 0.00 & $0 / 19$ & 0.00 \\
\hline $3 \mathrm{~ms}$ & $0 / 19$ & 0.00 & $0 / 19$ & 0.00 \\
\hline $6 \mathrm{~ms}$ & $0 / 19$ & 0.00 & $0 / 19$ & 0.00 \\
\hline $12 \mathrm{~ms}$ & $3 / 19$ & 15.8 & $1 / 19$ & 5.26 \\
\hline Chi square $\left(\chi^{2}\right)$ & \multicolumn{4}{|c|}{0.343} \\
\hline P-value $<0.05$ & \multicolumn{4}{|c|}{052} \\
\hline
\end{tabular}

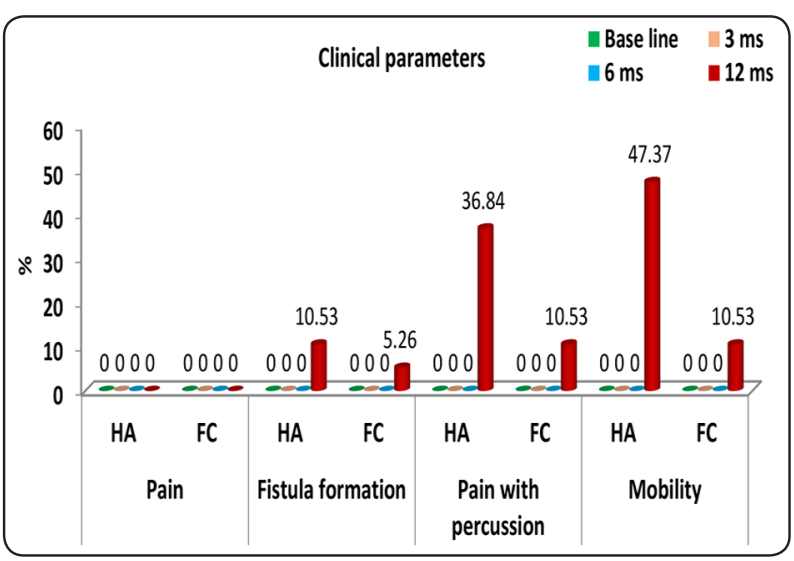

Fig. (2) Clinical evaluation of HA, FC groups according to presence of failure criteria at different follow-up periods
TABLE (3) Radiographic evaluation of HA, FC groups according to presence of external root resorption at different follow-up periods

\begin{tabular}{|c|c|c|c|c|}
\hline \multirow{2}{*}{} & \multicolumn{2}{|c|}{$\mathrm{HA}$} & \multicolumn{2}{c|}{$\mathrm{FC}$} \\
\cline { 2 - 5 } & $\mathrm{n} / \mathrm{N}$ & $\%$ & $\mathrm{n} / \mathrm{N}$ & $\%$ \\
\hline Base line & $0 / 19$ & 0.00 & $0 / 19$ & 0.00 \\
\hline $3 \mathrm{~ms}$ & $5 / 19$ & 26.32 & $0 / 19$ & 0.00 \\
\hline $6 \mathrm{~ms}$ & $7 / 19$ & 36.84 & $0 / 19$ & 0.00 \\
\hline $12 \mathrm{~ms}$ & $12 / 19$ & 63.16 & $1 / 19$ & 5.26 \\
\hline Chi square $\left(\chi^{2}\right)$ & \multicolumn{4}{|c|}{2.046} \\
\hline P-value $<0.05$ & \multicolumn{5}{|c|}{0.563} \\
\hline
\end{tabular}

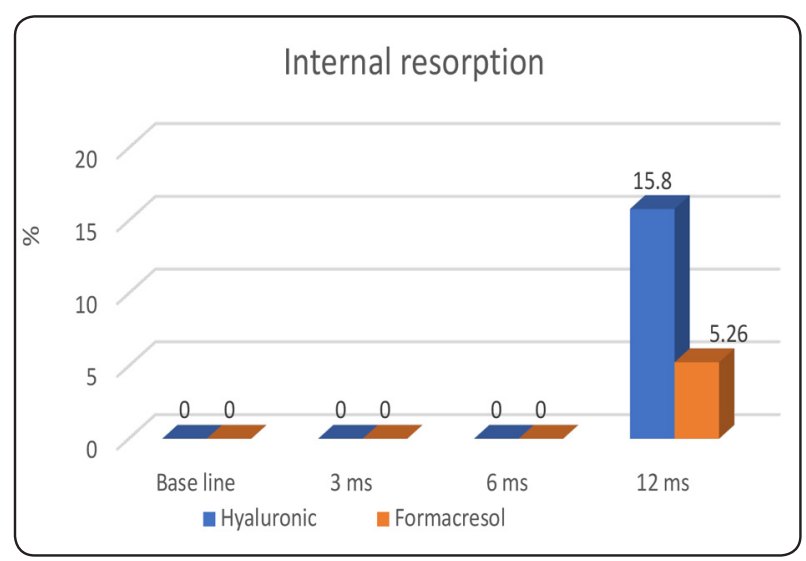

Fig. (3) Radiographic evaluation of HA, FC groups according to presence of internal resorption at different follow-up periods 
TABLE (4) Radiographic evaluation of HA, FC groups according to measurement of widening of PDL space at different follow-up periods

\begin{tabular}{|c|c|c|c|c|c|c|}
\hline & \multicolumn{2}{|c|}{ HA } & \multicolumn{2}{c|}{ FC } & \multirow{2}{*}{ Wilcoxon W values } & (Between techniques) \\
\cline { 2 - 5 } & Mean & SD & Mean & SD & \\
\hline Base line & $1.81^{\mathrm{a}}$ & 0.13 & $0.99^{\mathrm{d}}$ & 0.11 & -5.27 & $<0.0001^{* *}$ \\
\hline $3 \mathrm{~ms}$ & $1.34^{\mathrm{c}}$ & 0.04 & $1.06^{\mathrm{c}}$ & 0.11 & -5.189 & $<0.0001^{* *}$ \\
\hline $6 \mathrm{~ms}$ & $1.16^{\mathrm{d}}$ & 0.24 & $1.18^{\mathrm{b}}$ & 0.04 & -0.847 & 0.397 \\
\hline $12 \mathrm{~ms}$ & $1.45^{\mathrm{b}}$ & 0.05 & $1.29^{\mathrm{a}}$ & 0.05 & -5.058 & $<0.0001^{* *}$ \\
\hline $\mathrm{p}$ & \multicolumn{2}{|c|}{$<0.0001^{* *}$} & \multicolumn{2}{c}{$<0.0001^{* *}$} & & \\
\hline
\end{tabular}

$a, b ;$ means significant difference (same column) between time interval at $P \leq 0.05$

**, means significant difference at $P \leq 0.05$

TABLE (5) Radiographic evaluation of HA, FC groups according to furcation bone radio-density at different follow-up periods

\begin{tabular}{|c|c|c|c|c|c|c|}
\hline \multirow{2}{*}{} & \multicolumn{2}{|c|}{ HA } & \multicolumn{2}{c|}{ FC } & \multirow{2}{*}{$\begin{array}{c}\text { Wilcoxon W } \\
\text { values }\end{array}$} & $\begin{array}{c}\text { P value (Between } \\
\text { techniques) }\end{array}$ \\
\cline { 2 - 7 } & Mean & SD & Mean & SD & -1.18 & 0.24 \\
\hline Base line & $96.15^{\mathrm{a}}$ & 0.85 & $96.68^{\mathrm{a}}$ & 2.30 & -4.60 & $0.00^{* *}$ \\
\hline $3 \mathrm{~ms}$ & $75.96^{\mathrm{c}}$ & 4.11 & $68.40^{\mathrm{b}}$ & 2.88 & -5.271 & $0.00^{* *}$ \\
\hline $6 \mathrm{~ms}$ & $82.71^{\mathrm{b}}$ & 3.76 & $63.82^{\mathrm{c}}$ & 3.52 & -4.438 & $0.00^{* *}$ \\
\hline $12 \mathrm{~ms}$ & $41.40^{\mathrm{d}}$ & 7.39 & $52.84^{\mathrm{d}}$ & 3.23 & & \multicolumn{2}{c}{$<0.0001^{* *}$} \\
\hline
\end{tabular}

${ }^{a, b}$; means significant difference between time interval at $P \leq 0.05$

**, means significant difference at $P \leq 0.05$

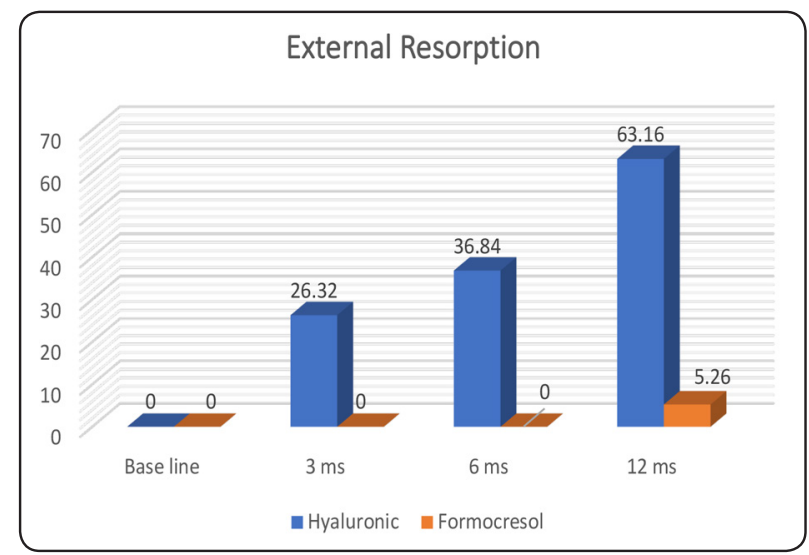

Fig. (4) Radiographic evaluation of HA, FC groups according to presence of external root resorption at different follow-up periods

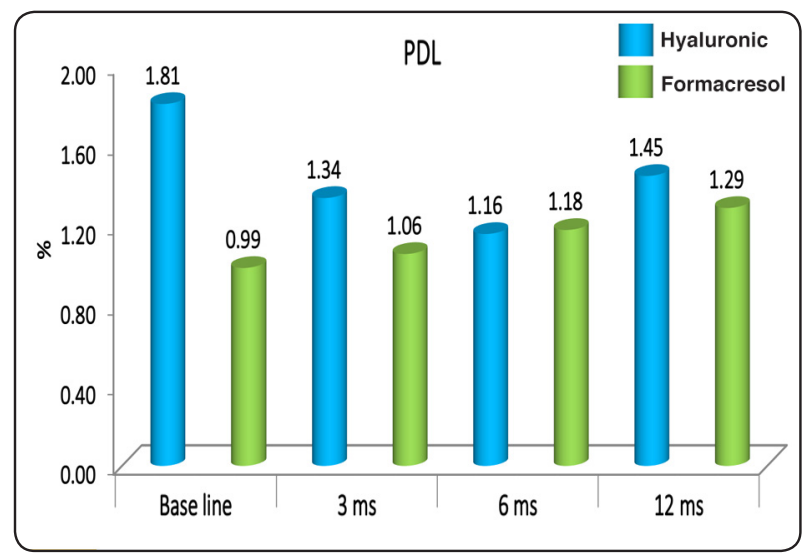

Fig. (5) Radiographic evaluation of HA, FC groups according to measurement of widening of PDL space at different follow-up periods. 


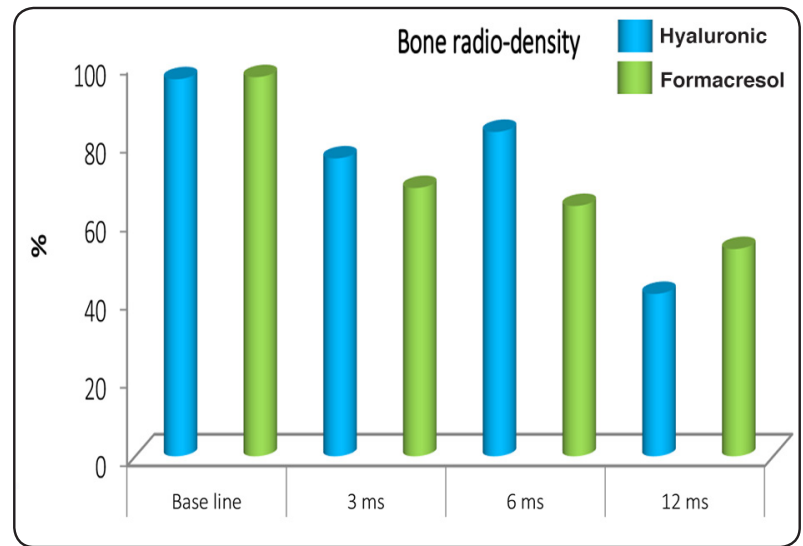

Fig. (6) Radiographic evaluation of HA, FC groups according to furcation bone radio-density at different follow-up periods

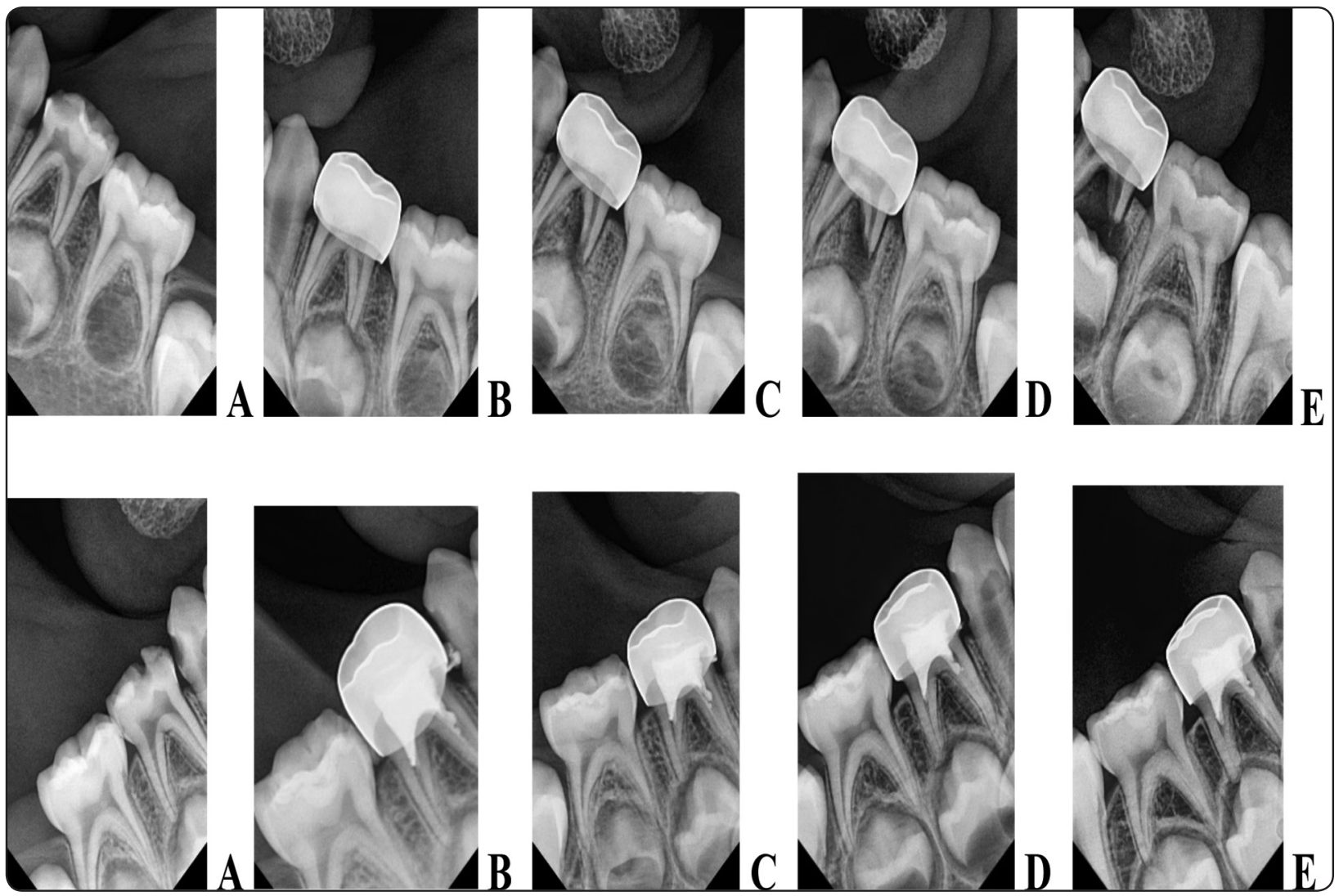

Fig. (7) Both groups: Preoperative intraoral peri-apical (IOPA) radiographs showing deep carious lesions of lower first primary molar indicated for pulpotomy (A), LT side (HA group) and RT side (FC group). IOPA radiographs post-pulpotomies filling and stainless steel crown restorations (B). Post-IOPA radiographs at 3, 6 and 12 months (C-E). 


\section{DISCUSSION}

The present study was conducted on forty primary mandibular molars in twenty children to compare the clinical \& radiographic effect of HA gel and $1 / 5$ concentration of FC as a vital pulpotomy agent. The vital pulpotomy is a prevailing one-stage treatment which aims to preserve the vitality of the radicular pulp tissue, thus avoiding more invasive endodontic treatment and preserving the integrity and health of oral tissue architecture.

Children between 4 to 8 years of age were selected for this study, irrespective of their sex, and economic or social background, this is in accordance with Beltagy \& Yasser ${ }^{(34)}$ and El-Meligy et al. ${ }^{(35)}$ This age group was selected to avoid the lack of cooperation in younger age group and the physiological root resorption in the elder children. Moreover, it was chosen to keep the primary molars until exfoliation because untimely loss of primary molars is one of the contributing factors to space loss and malocclusion. The selected cases had bilateral deep carious primary molars in order to perform treatment with the same environmental variables for both groups and, as much as possible, to overcome potential bias and confounding variables. In the current study, the selection and treatment of teeth were done in accordance with the AAPD guidelines for pulp therapy in primary teeth and immature permanent teeth. ${ }^{(36)}$

In the current study, formocresol (diluted FC 1:5) was selected as the control group because it is still considered to be the gold standard for primary teeth pulpotomies due to its ease of use, availability, bacteriostatic \& fixative properties moreover, it has high clinical success rates. ${ }^{(8,37,38)}$ Hyaluronic acid is a biocompatible and biodegradable substance; it has an anti-aging effect as it promotes collagen synthesis, preserves fibroblast integrity, activates growth factors, and suppresses collagenase production. ${ }^{(39)}$ Another aspect that can influence HA action is its configuration, which allows for more area and volume for cell attachment, resulting in more newly developed tissue. A wide range of commercially produced HA derivatives have been developed, including films, microspheres, fibers, and hydrogels. (40) In the present study, high molecular weight $\mathrm{HA}$ in a gel form was used because it recorded promising result of bone fracture healing when combined with fibroblast growth factor-2. ${ }^{(41)}$ In addition, the gel form allowed easily mixing of HA with zinc oxide powder and facilitated handling the mix. Zinc oxide powder was chosen to be blended with HA and applied to the pulp tissue as it is non-irritant to the vital pulp tissue. Moreover, HA possesses anti-inflammatory and regenerative properties, thus it was chosen as the experimental group to assess its efficacy as a pulpotomy medicament. The pulpotomy technique in this study was performed by a single operator, providing the benefit of a strictly consistent and reproducible technique.

All pulpotomized molars were followed up clinically at 3,6 and 12-months follow-up periods. After 3, 6 months follow up period, the results of the present study showed $100 \%$ clinical success rate for all Formocresol and hyaluronic acid gel treated pulpotomized teeth. There were no signs or symptoms of clinical failure in any of the two groups as there was no spontaneous pain, no tooth mobility, nor fistulous tract formation. These results agreed with Ansari et al. ${ }^{(8)}$ and Verma et al. ${ }^{(2)}$ This high overall performance in both groups could be related to precise case selection, isolation, high aseptic rules, proper protocols, and appropriate use of the two medications. Also, stainless-steel crowns used in this study provide one of the most efficient coronal seals toward microbial seepage in primary molars.

After 12 months follow-up period, formocresol group showed clinical success rates of $89.5 \%$, $94.7 \%$ and $89.5 \%$ by evaluation of teeth mobility, fistulous tract formation and pain with percussion, 
respectively. These findings are consistent with those of Elbardissy \& El-Sayed ${ }^{(42)}$ study in which biodentine showed $100 \%$ clinical success at all follow up periods, however FC showed $95.1 \%$ clinical success. This may attributed to the fact that the fixation of pulp tissue using FC is never complete. In relation to presence of spontaneous pain, the clinical success rate was $100 \%$ after 12 months which is agreed with Godhi et al. ${ }^{(37)}$ and Yildiz \& Tosun. ${ }^{(38)}$ This finding is credited to the antimicrobial action of FC which is due to chemical bonding with the proteins of microorganisms.

Regarding hyaluronic acid group, after 12 months follow-up period, there was clinical success rates of $52.63 \%, 89.5 \%$ and $63.16 \%$ by evaluation of teeth mobility, fistulous tract formation and pain with percussion, respectively. This finding is related to the complete resorption of hyaluronic acid; it is stable for approximately 8 months. These results coincide with Pilloni et al. ${ }^{(43)}$ Study which reported that HA may show resorption over time and gingival recession defects may recur. On the other hand, the clinical success rate was $100 \%$ after 12 months by evaluating the spontaneous pain; this is agreed with Pistorius et al. ${ }^{(44)}$, Lobato et al. ${ }^{(45)}$ and Lima et al. (46) These findings imply that the anti-inflammatory and bacteriostatic properties of HA may play a role in pulpal inflammation reduction.

Atthree-andsix-monthsradiographicevaluations, no internal resorption was noted in any of the two groups with no statistically significant difference. while at 12 months follow-up, $15.8 \%$ of hyaluronic acid treated cases showed internal resorption; this may be explained by the fact that the longevity of hyaluronic acid is approximately 8 months. Also, $5.3 \%$ of formocresol treated cases reported internal resorption; this finding is comparable to Jayaraman et al . (47) This may attributed to the fixative effect of $\mathrm{FC}$ as the mummified tissue act as a barrier between the pulp tissue $\&$ the base material as the direct application of zinc oxide-eugenol base over the pulp tissue may result in release of free eugenol from the zinc eugenol mixture so led to chronic inflammation of pulp tissue.

Radiographically, regarding external root resorption, there was about $63 \%$ of hyaluronic acid group showed external root resorption at 12 months follow-up period; this may be explained by the short half-life of the hyaluronic acid. While only $5.3 \%$ of FC group had external root resorption; this result is in accordance with Ansari \& Ranjpour. ${ }^{(48)}$ and Chandrashekhar \& Shashidhar. (49) This may be explained by FC antiseptic and fixative properties as it mummifies a broad zone of the remaining radicular pulp after removal of coronal pulp tissue.

Formocresol group showed increase in the periodontal ligament space at 3, 6, 12 month evaluation periods, however HA group showed a decrease in PDL space at 3,6 months followup only then slight increase occur at 12 months follow-up; the difference between the two groups was highly statistically significant. The increase in PDL width in FC group may attributed to the fact that FC is able to fix superior parts of the radicular pulp tissue rather than stimulating healing, so the apical part displayed inflammatory characteristics, increasing the likelihood of periapical changes. This result agreed with Durmus \& Tanboga. ${ }^{(50)}$ study in which furcal radiolucency and PDL widening were higher in the FC group than Diode Laser, and Ferric Sulphate groups. Also, this finding agreed with Abuelniel \& Eltawi. (51) who concluded that Ferric sulphate, mineral trioxide aggregate and Calcium hydroxide and iodoform paste provide clinically acceptable alternative to FC in vital pulp therapy in primary teeth.

The significant decrease of the PDL space in the HA group may attributed to hyaluronan which play a potential role in periodontal tissue healing as it has viscoelastic properties which help strengthening of the extracellular matrix. All these rheological characteristics encourage cellular migration and 
proliferation, which aids in the healing process. These findings are in line with Sahayata Vishal et al. ${ }^{(52)}$ who concluded that local application of 0.2 $\%$ HA gel supplement to non-surgical periodontal treatment provides a major enhancement in gingivitis by decreasing gingival bleeding and crevicular fluid flow because it aids in the reduction of lysozomal enzymes such as hyaluronidase and chondroitinase.

Regarding radio-density of bone at the furcation area, formocresol group showed gradual increase in furcal radiolucency through the follow-up periods. These results agree with Salem \& Farouk ${ }^{(53)}$ study in which $12.5 \%$ of the FC group was associated with internal resorption and a furcation involvement compared to $6 \%, 11 \%$ of the $2.5 \% \mathrm{NaOCl}$ and the $5 \%$ $\mathrm{NaOCl}$ pulpotomy treated groups respectively. This may attributed to seepage of the smaller size of the formocresol molecules into the periapical region via the pulpal canals or into the furcation area through the accessory canals. On the other hand, HA group showed decrease in furcal radiolucency especially at 6 months follow-up period; this result is agreed with Lobato et al. ${ }^{\left({ }^{45}\right)}$ These findings are most likely the result of regenerative effect which HA can promote, by encouraging adhesion, migration, proliferation, and cellular activation as it can store and deliver growth factors.

To our knowledge, the present study may be the first study comparing HA with FC as pulpotomy agents in primary teeth. According to the results of this study, hyaluronic acid can be used as substitute to formocresol as a pulpotomy medicament which yielding satisfactory results clinically and radiographically. However, it necessitates further clinical and histologic studies to be carried out with a longer follow up period to make definitive conclusions. The current study had few limitations which includes small sample size and short followup period while it could serve as a foundation for future researches in this field, with a longer followup and more participants.

\section{LIMITATIONS}

HA gel was difficult to be applied on the pulp stumps, so it was mixed with zinc-oxide powder. Moreover, there was difficulty to obtaining patients having all inclusion criteria of the study.

\section{RECOMMENDATIONS}

Further histopathlogical studies should be done to investigate HA effects on primary pulp tissues. Also, longer clinical follow-up period till the time of tooth shedding is recommended for more accurate evaluation of HA as a pulpotomy material in primary molars.

\section{CONCLUSION}

The current study showed that the clinical and radiographic success rates of HA are comparable to that of Formocresol for primary molars over a 12-month follow-up period. Hence it can be concluded that HA can be used as reliable alternatives to Formocresol for the pulpotomy procedures in primary teeth.

\section{REFERENCES}

1. Ibricevic H. and Al-Jame Q.: Ferric sulphate and formocresol in pulpotomy of primary molars: long term follow-up study. J Eur of Pediatr Dent, 2003; 4: 28-32.

2. Verma B., Choudhari S., Goyal S., Vispute G., Bharti K. and Choudhari S.: Comparative evaluation of success of pulpotomy in primary molars treated with Formocresol, Pulpotec and Biodentine- 6 month follow up study. Int J App Dent Sci, 2019; 5: 77-82.

3. Unqueira M., Cunha N., Caixeta F., Marques N., Oliveira T., Moretti A. and Sakai V.: Clinical, radiographic and histological evaluation of primary teeth pulpotomy using MTA and ferric sulfate. Braz Dent J, 2018; 29:159-165.

4. Ahmed H.: Pulpectomy procedures in primary molar teeth. Eur J General Dent, 2014; 3: 3-10.

5. Coll J., Seale N., Vargas K., Marghalani A., Al Shamali S. and Grahamet L.: Primary tooth vital pulp therapy: a systematic review and meta-analysis. Pediatr Dent, 2017; 39:16-123. 
6. Sonmez D., Sari S. and Cetinbaş T.: A comparison of four pulpotomy techniques in primary molars: a long-term follow-up. J Endod, 2008; 34: 950-955.

7. El-Meligy O., Abdalla M., El-Baraway S., El-Tekya M. and Dean J.: Histological evaluation of electrosurgery and formocresol pulpotomy techniques in primary teeth in dogs. J Clin Pediatr Dent, 2002; 26(1): 81-85.

8. Ansari G., Morovati S., and Asgary S.: Evaluation of four pulpotomy techniques in primary molars: A randomized controlled trial. Iran Endod J,2018: 13(1):7-12.

9. Simancas Pallares M., Caballero A., and Luna L.: Mineral trioxide aggregate in primary teeth pulpotomy. A systematic literature review. Med Oral Patol Oral Cir Bucal, 2010 ;15(6): 942-946.

10. Zarzar P., Rosenblatt A., Takahashi C., Takeuchi P. and Costa Júnior L.: Formocresol mutagenicity following primary tooth pulp therapy: an in vivo study. J dent, 2003; 31(7): 479-485.

11. Sunitha B., Puppala R., Kethineni B., Mallela M., Peddi R. and Tarasingh P.: Clinical and radiographic evaluation of four different pulpotomy agents in primary molars: A longitudinal study. Int J clin pediatr dent,2017; 10(3): 240-244.

12. Kakarla P., Avula J., Mellela G., Bandi S. and Anche S.: Dental pulp response to collagen and pulpotec cement as pulpotomy agents in primary dentition: A histological study. J conserv dent, 2013: 16(5): 434-438.

13. Guven Y., Aksakal S., Avcu N., Unsal G., Tuna E. and Aktoren O.: Success rates of pulpotomies in primary molars using calcium silicate-based materials: A randomized control trial. BioMed Res Int, 2017: doi: $10.1155 / 2017 / 4059703$.

14. Gisoure E.: Comparison of three pulpotomy agents in primary molars: a randomised clinical trial. Iran Endod J, 2011; 6(1): 11-14.

15. Prince C.: Roles of hyaluronan in bone resorption. BMC Musculoskelet Disord, 2004; 5(1): 1-3.

16. Falcone S., Palmeri D., and Berg R.: Rheological and cohesive properties of hyaluronic acid. Journal of Biomedical Materials Research Part A. J Biomed Mater Res A, 2006;76(4):721-728.

17. Linhao L., Qian Y., Jiang C., Lv Y., Liu W., Zhong L., Cai K., Li S. and Yang L.: The use of hyaluronan to regulate protein adsorption and cell infiltration in nanofibrous scaffolds. Biomaterials, 2012; 33(12): 3428-3445.

18. Liang J., Jiang D. and Noble P.: Hyaluronan as a therapeutic target in human diseases. Adv Drug Deliv Rev, 2016; 97: 186-203.
19. Dechert T., Ducale A., Ward S. and Yager D.: Hyaluronan in human acute and chronic dermal wounds. Wound Repair and Regen, 2006; 14(3): 252-258.

20. Kim J., Kim I., Cho T.,Lee K.,Hwang S., Tae G., Noh I., Lee S., Park Y. and Sun K.: Bone regeneration using hyaluronic acid-based hydrogel with bone morphogenic protein-2 and human mesenchymal stem cells. Biomaterials, 2007; 28(10): 1830-1837.

21. Pasquinelli G., Orrico C., Foroni L., Bonafè F., Carboni M., Guarnieri C., Raimondo S., Penna C., Geuna S., Pagliaro P., Freyrie A., Stella A., Caldarera C. and Muscari C.: Mesenchymal stem cell interaction with a non-woven hyaluronan- based scaffold suitable for tissue repair. J anat, 2008; 213(5): 520-530.

22. Hemshekhar M., Thushara R., Chandranayaka S., Sherman L., Kemparaju K. and Girish K.: Emerging roles of hyaluronic acid bioscaffolds in tissue engineering and regenerative medicine. Int J Biol macromol, 2016; 86: 917-928.

23. KretzF., Limberger I., and Auffarth G.: Corneal endothelial cell coating during phacoemulsification using a new dispersive hyaluronic acid ophthalmic viscosurgical device. J Cataract Refract Surg, 2014; 40(11): 1879-1884.

24. Vangelisti R., Pagnacco O. and Erra C.: Hyaluronic acid in the topical treatment of gingival inflammations: preliminary clinical trial. Transl AttualitaTerapeutica In, 1997;3: 1-7.

25. Dahiya P. and Kamal R.: Hyaluronic acid: a boon in periodontal therapy. N Am J med sci, 2013; 5(5):309-315.

26. Awartani F. and Tatakis D.: Interdental papilla loss: treatment by hyaluronic acid gel injection: a case series. Clin oral investg, 2016; 20(7): 1775-1780.

27. Romeo U., Palaia F., Galanakis A., Gaimari G., Tenore G., Vecchio A. and Polimeni A.: Oral soft tissue wound healing after laser surgery with or without a pool of amino acids and sodium hyaluronate: a randomized clinical study. Photomed laser surg, 2014; 32(1): 10-16.

28. Koray M., Ofluoglu D., Onal E., Ozgul M., Ersev H., Yaltirik M. and Tanyeri H.: Efficacy of hyaluronic acid spray on swelling, pain, and trismus after surgical extraction of impacted mandibular third molars. Int $\mathbf{J}$ oral Maxillofac surg, 2014: 43(11): 1399-1403.

29. Gocmen G., Gonul O., Oktay N., Yarat A. and Goker $\mathrm{K}$.: The antioxidant and anti-inflammatory efficiency of hyaluronic acid after third molar extraction. J CranioMaxillofac Surg, 2015; 43(7):1033-1037.

30. Inuyama, Y ., Kitamura C., Nishihara T., Morotomi T., Nagayoshi M., Tabata Y., Matsuo K., Chen K. and 
Terashita M.: Effects of hyaluronic acid sponge as a scaffold on odontoblastic cell line and amputated dental pulp. J Biomedi Mat Res B Appl, 2010; 92(1): 120-128.

31. Gutowska A., Jeong B. and Jasionowski M.: Injectable gels for tissue engineering. The Anat Rec, 2001;263(4): 342-349.

32. Engler, A., Sen S., Sweeney H. and Discher D.: Matrix elasticity directs stem cell lineage specification. Cell, 2006; 126(4): 677-689.

33. Xu X., Jha A., Duncan R. and Jia X.: Heparin-decorated, hyaluronic acid-based hydrogel particles for the controlled release of bone morphogenetic protein 2. Acta biomater, 2011;7(8): 3050-3059.

34. Beltagy, T. \& Yasser S. Clinical, Radiographical and Histopathological Evaluation of Amniotic Membrane Allograft Pulpotomy in Primary teeth. Egyp Dent J 2019; 65: 3179-3197.

35. El Meligy O., Alamoudi N., Allazzam S. \& El-Housseiny A. Biodentine TM versus formocresol pulpotomy technique in primary molars: a 12-month randomized controlled clinical trial. BMC oral health 2019;19(1): 1-8.

36. American Academy of Pediatric Dentistry. Pulp therapy for primary and immature permanent teeth. The Reference Manual of Pediatric Dentistry. Chicago, Ill.: American Academy of Pediatric Dentistry; 2020:384-392.

37. Godhi B, Sood P, Sharma A. Effects of mineral trioxide aggregate and formocresol on vital pulp after pulpotomy of primary molars: An in vivo study. Contemp Clin Dent. 2011;2(4):296-301.

38. Yildiz E, Tosun G. Evaluation of formocresol, calcium hydroxide, ferric sulfate, and MTA primary molar pulpotomies. Eur J Dent. 2014;8(2):234-240.

39. Wang F, Garza LA, Kang S, Varani J, Orringer J, Fisher G, et al. In vivo stimulation of de novo collagen production caused by cross-linked hyaluronic acid dermal filler injections in photodamaged human skin. Arch Dermatol 2007; 143:155-163.

40. Solchaga L, Dennis J, Victor M, Goldberg V, Caplan A. Hyaluronic acid-based polymers as cell carriers for tissueengineered repair of bone and cartilage. J Orthop Res, 1999; 17:205-213.

41. Radomsky M, Aufdemorte T, Swain L, Fox W, Spiro R, Poser J. Novel formulation of fibroblast growth-2 in a hyaluronan gel accelerates fracture healing in non human primates. J Orthop Res 1999;17:607-614.

42. Elbardissy A., \& El Sayed M. Clinical And Radiographic Evaluation Of Biodentine Versus Formocresol In Vital
Pulpotomy Of Primary Molars (A Randomized Control Clinical Trial). Egyp Dent J 2019; 65: 9-20.

43. Pilloni, A., Schmidlin, P., Sahrmann, P., Rojas M. Effectiveness of adjunctive hyaluronic acid application in coronally advanced flap in Miller class I single gingival recession sites: a randomized controlled clinical trial. Clin Oral Invest 2019;23: 1133-1141.

44. Pistorius A., Martin M., Willershausen B., \& Rockmann P. The clinical application of hyaluronic acid in gingivitis therapy. Quintessence Int 2005; 36(7):531-538.

45. Lobato J, Santos Vilhena M, Izidoro C, Alves R, Proença L. Single application of $0.8 \%$ hyaluronic acid as a coadjuvant of nonsurgical treatment in nonsmoking patients with periodontitis: A split-mouth, randomized, controlled pilot clinical trial. J Indian Soc Periodontol 2019;23:545-548.

46. Lima M., Nobre Á., Silva F., de Araújo Sales E., de Sousa Lopes M., Mendes T., et al. The use of Hyaluronic Acid as an adjuvant Therapeutic Approach to Non-Surgical Periodontal Therapy for Periodontitis. Braz J Develop. 2020; 6(5): 29219-29234.

47. Jayaraman J, Nagendrababu V, Pulikkotil SJ, Veettil SK, Dhar V. Effectiveness of formocresol and ferric sulfate as pulpotomy material in primary molars: a systematic review and meta-analysis with trial sequential analysis of randomized clinical trials. Quintessence Int. 2020;51(1):3848. doi: 10.3290/j.qi.a43617. PMID: 31781690.

48. Ansari G., \& Ranjpour M. Mineral trioxide aggregate and formocresol pulpotomy of primary teeth: a 2-year followup. Int Endo J 2010; 43(5): 413-418.

49. Chandrashekhar S, Shashidhar J. Formocresol, still a controversial material for pulpotomy: A critical literature review. J Res Dent 2014;2:114-124.

50. Durmus B, Tanboga I. In vivo evaluation of the treatment outcome of pulpotomy in primary molars using diode laser, formocresol, and ferric sulphate. Photomed Laser Surg. 2014;32(5):289-295. doi:10.1089/pho.2013.3628

51. Abuelniel G., \& Eltawil S. Clinical and Radiographic Assessment of Pulpotomy Materials in Primary Molars. Egy Dent J 2018; 64: 951-962.

52. Sahayata V., Bhavsar N., \& Brahmbhatt N. An evaluation of $0.2 \%$ hyaluronic acid gel (Gengigel $\AA$ ) in the treatment of gingivitis: a clinical \& microbiological study. Oral health and dental management 2014; 13(3): 779-785.

53. Salem G, Farouk Y. Clinical and radiographic evaluation of testing different concentrations of sodium hypochloride as vital pulpotomy treatment in primary teeth: a randomized controlled trial. J Arab Soc Med Res 2017;12;106-112. 